\title{
Communication
}

\section{Thermal Jacket Design Using Cellulose Aerogels for Heat Insulation Application of Water Bottles}

\author{
Hai M. Duong *, Ziyang Colin Xie, Koh Hong Wei, Ng Gek Nian, Kenneth Tan, Hong Jie Lim, \\ An Hua Li, Ka-Shing Chung and Wen Zhen Lim \\ Department of Mechanical Engineering, National University of Singapore, Singapore 9 Engineering Drive 1, \\ EA-07-08, Singapore 117575, Singapore; colinxie@u.nus.edu (Z.C.X.); a0124203@u.nus.edu (K.H.W.); \\ a0125030@u.nus.edu (N.G.N.); a0124334@u.nus.edu (K.T.); a0124479@u.nus.edu (H.J.L.); \\ anhua.li@u.nus.edu (A.H.L.); chungkashing@u.nus.edu (K.-S.C.); limwenzhen@yahoo.com.sg (W.Z.L.) \\ * Correspondence: mpedhm@nus.edu.sg; Tel.: +65-9769-9600
}

Received: 2 November 2017; Accepted: 17 November 2017; Published: 23 November 2017

\begin{abstract}
Thermal jacket design using eco-friendly cellulose fibers from recycled paper waste is developed in this report. Neoprene as an outmost layer, cellulose aerogels in the middle and Nylon as an innermost layer can form the best sandwiched laminate using the zigzag stitching method for thermal jacket development. The temperature of the ice slurry inside the water bottle covered with the designed thermal jackets remains at $0.1{ }^{\circ} \mathrm{C}$ even after $4 \mathrm{~h}$, which is the average duration of an outfield exercise. Interestingly, the insulation performance of the designed thermal jackets is much better than the commercial insulated water bottles like FLOE bottles and is very competition to that of vacuum flasks for a same period of $4 \mathrm{~h}$ and ambient conditions.
\end{abstract}

Keywords: cellulose aerogel; thermal conductivity; water bottle; thermal jacket design; heat insulation

\section{Introduction}

Soldiers in the Armed Forces (AF) regularly can embark on vigorous physical activities in a hot and humid training environment. The military canteen is an essential piece of equipment to contain fluid, which provides sufficient rehydration for each soldier during training and prevents the onset of heat-related injuries [1]. Heat injury is often a consequence of prolonged activity under hot and humid conditions, which is exacerbated by dehydration and failure to replenish lost bodily fluids. Its severity ranges from mild heat cramps to heat exhaustion and serious heat stroke, which is a medical emergency and can potentially be fatal if not treated immediately [1]

Despite an extensive list of heat management guidelines, heat injuries still occur from time to time in the AF. Certainly, it can be done more to prevent the very occurrence of heat injury during training. Several sports science studies $[2,3]$ have stated that lower core body temperature and longer work tolerance time can be achieved by ingesting ice slurry before and during physical exercise. Ingestion of ice slurry can regulate body temperature more effectively than consumption of chilled water. This is because of the higher cooling capacity of ice particles, which can absorb heat at a near constant phase-change temperature [2,3]. Therefore, a lightweight and highly insulated water bottle to store the ice slurry is desired.

The current AF military canteen is made of high-density polyethylene (HDPE) material, which is lightweight, durable, and low cost [4]. However, HDPE has rather high thermal conductivity and maintains poorly chilled beverages [4]. Commercial FLOE bottles (Teknicool Ltd, Auckland, New Zealand) are designed for sports activities such as cycling. The FLOE bottles have an air gap between the inner and outer materials of the bottles, which can reduce heat transfer through conduction. But the FLOE bottle cannot keep ice slurry for a prolonged period in outfield [5]. By creating a layer of vacuum between the inner and outer surface, commercial vacuum flasks can eliminate heat transfer 
via conduction and convection and maintain ice retention for up to a few days [6]. However, there is little or no available research on the applicability of the vacuum flasks under the walking and running conditions of military purposes. The vacuum flasks also having high cost and heavy weight may not be the best alternative replacing the current military canteens $[5,6]$.

As the commercial thermal insulated bottles are not optimized for military applications in terms of thermal insulating properties, mechanical properties and cost consideration, another engineering solution is to develop a lightweight and cost-effective thermal jacket wrapped on the existing military canteens. Beer Koozie utilizes a foam sleeve wrapped on bottles to provide thermal insulation and prevent condensation on the surface of the bottle, which can slow down heat transfer [7]. The effect of condensation shows that the temperature changes of water inside the bottle in an environment with $40 \%$ and $85 \%$ relative humidity is $39{ }^{\circ} \mathrm{C}$ and $44{ }^{\circ} \mathrm{C}$, respectively [1,7]. So Koozie sleeves cannot keep the low temperature of the military canteen water.

Among common insulation materials such as polystyrene foam $[7,8]$, using cellulose aerogels from paper waste [9-12] can be a better insulator choice. The cellulose aerogels are environmentally friendly and are made of the cellulose fibers from recycled waste paper through freeze-drying processes [9-12]. The cellulose aerogels have the low thermal conductivity $(0.03-0.04 \mathrm{~W} / \mathrm{m} \cdot \mathrm{K})$ and less toxic emissions and require less harmful chemicals during the fabrication [9-12]. The cellulose aerogels has the lowest density of $0.04 \mathrm{~g} / \mathrm{cm}^{3}$, which is lighter than other common insulation materials, and perform similar insulation results $[10,12]$.

So this communication focuses on using cellulose aerogel to design an insulated jacket for the military canteens to prolong ice slurry to active military personnel in training or operation. However, the cellulose aerogels have low tensile strength, and their structures can be damaged easily upon rough handling [9-12]. It is thus necessary to sandwich the cellulose aerogels between two protective layers so that the insulated jacket can be more durable. The commercial synthetic fabrics and $10-\mathrm{cm}$ thick cellulose aerogels are chosen. It is clear that increasing the thickness can increase the thermal resistance of the insulated jacket $[10,12]$. However, the thick insulated jacket has negative implications on its weight and user-friendliness. The final jacket design is aimed to meet following points: (i) The design of the insulated jacket can conform well to the contours of the military canteens, (ii) The cellulose aerogel needs to be properly fitted and secured within the two protective layers to prevent its structure damage, (iii) The bottle must be inserted and removed from the jacket easily, and (iv) Heat transfer should be minimized and cannot counter the insulating effects of the cellulose aerogel. The heat insulation performance of the developed insulated jacket is also compared with commercial FLOE sport bottles and vacuum flask bottles in this work.

\section{Results}

From Figure 1 below, the vacuum flask yields the best thermal insulating results with the least temperature increase after $4 \mathrm{~h}$, followed by the military canteen that is wrapped by the insulated jacket. The temperature of the content inside both bottles is approx. $0.1-0.2{ }^{\circ} \mathrm{C}$ after $4 \mathrm{~h}$, which proves that they can maintain the ice slurry inside chilled. The insulation performance of the FLOE bottle comes next whereby the significant temperature rise is observed after $1 \mathrm{~h}$. The military canteen without the insulated jacket shows a significant increase in temperature after $30 \mathrm{~min}$, the worst heat insulation performance. The FLOE bottle and the military canteen without the insulated jacket cannot keep the ice slurry inside after $3 \mathrm{~h}$ and $1 \mathrm{~h}$, respectively. Despite having the best result, the vacuum flask posed some concerns in terms of heavier weight load and higher costs when compared with the other 3 in Appendix A Table A1 Hence it is not ideal to replace the current military canteens that are used by the soldiers with the vacuum flask bottles. From the Figure 1 and the Appendix A, it is concluded that the thermal jacket using the cellulose aerogels is designed successfully and that the simple but effective engineering solution for the heat insulation of the military canteens is validated. 


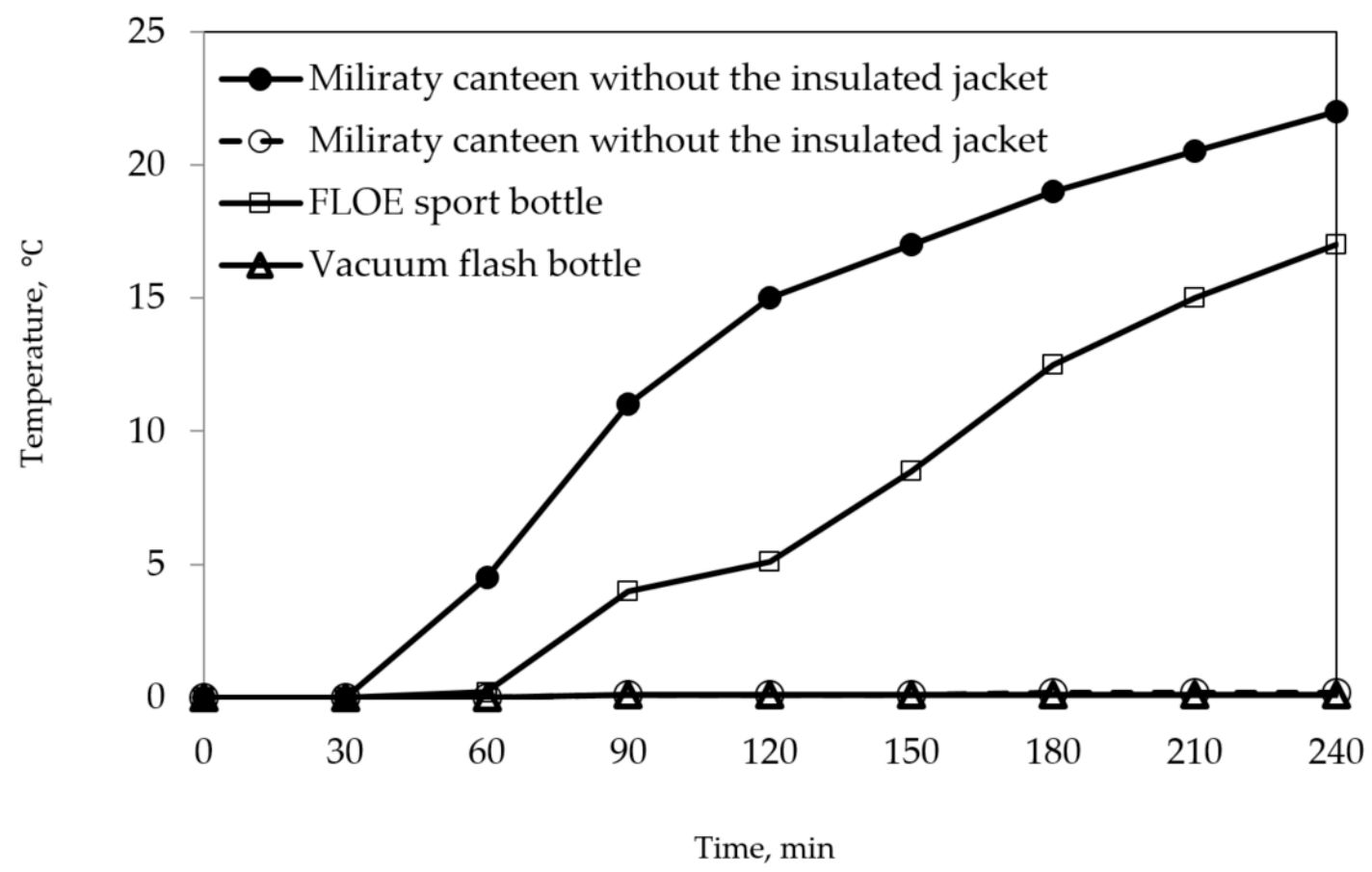

Figure 1. Heat insulation performance of various insulated bottles during $4 \mathrm{~h}$ testing.

\section{Discussion}

\subsection{Advantages of the Developed Thermal Jacket}

This developed insulated jacket can address the issues of previous thermal jacket designs. Assembling the design from multiple pieces ensures that the insulated jacket can fit very well the complicated contours of the bottle. The aerogel is tightly secured in place between two fabric layers to resolve the collapsing. It is much easier to insert or remove the military canteen, as it merely needs to be pulled out or pushed in before closing the zipper of the insulated jacket. The zipper length is optimized to reduce the heat transfer from the zipper. The insulated jacket also uses environmentally friendly cellulose fibers from recycled paper waste. When considering the high amounts of paper waste that is generated annually, recycling helps to reduce material wastage and lower greenhouse emissions. This green initiative can also reflect positively on social responsibility.

The mass production cost is estimated in the Appendix A Table A2. Figure 2 shows the cost estimation and the ice slurry temperature after $4 \mathrm{~h}$ of four different bottles. It is evident that the insulated military canteen has the preferred combination of the low price and the excellent heat insulation performance. Due to the ultra-lightweight cellulose aerogel that is used as the central layer, the total weight of the insulated jacket is 2.5 times and 1.4 time lighter than that of the vacuum flask the FLOE bottles, respectively. The total unladed weight of the insulated jacket and the military canteen is $360 \mathrm{~g}$, of which $200 \mathrm{~g}$ is the weight of the designed jacket. In comparison, the vacuum flask with the same capacity and no ice slurry weighs $900 \mathrm{~g}$, while two FLOE bottles with $500 \mathrm{~mL}$ capacity for each weighs $500 \mathrm{~g}$ in total. 


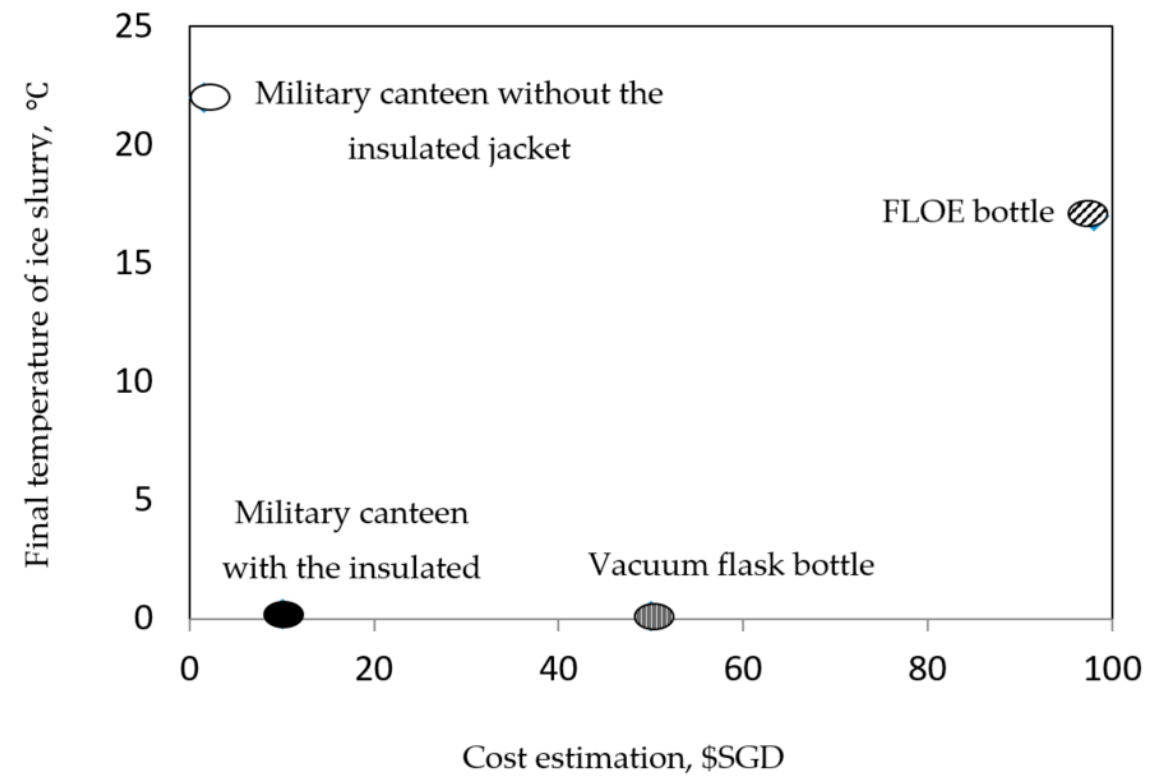

Figure 2. Comparison of the cost and heat insulation performance after $4 \mathrm{~h}$ of various bottles having the same 1-L capacity.

\subsection{Limitations of Thermal Jacket Design}

The insulated military canteen may be considered bulky by few end-users because the insulated jacket adds approx. $3 \mathrm{~cm}$ to the thickness of the military canteen. This is largely due to the $1.5 \mathrm{~cm}$ thick aerogel layer and $0.3 \mathrm{~cm}$ neoprene outer layer in the jacket design. Further design improvement may reduce more the thickness of the jacket and improve the insulated military canteen ergonomics. Currently we cannot determine the accurate technical service life of the insulated military canteen. So cyclic fatigue testing, pierce resistance, abrasion resistance, tear resistance, and ultraviolet (UV) resistance tests are desired in the future work.

Finally, there is no capacity for mass laboratory production of the cellulose aerogels used in this insulated jacket. In this project, the cellulose aerogels were laboriously produced in a small lab scale. The electrical overheads contribute to $60 \%$ of the total cost in the Appendix A Table A2, which is an incredibly high proportion for a mass manufactured product. Hence a better aerogel production method must be found for the mass production to be feasible.

\section{Materials and Methods}

\subsection{Fabrication of Cellulose Aerogels}

$12 \mathrm{~g}$ of cellulose fibers is added into $1.2 \mathrm{~L}$ of the deionized (DI) water, stirred thoroughly and placed in an ultrasonic processor for $15 \mathrm{~min}$ at maximum power. After $15 \mathrm{~min}$, the obtained suspension is removed from the ultrasonic processor to cool down to room temperature using a water bath. Kymene cross-linker is added to the mixture and it is subjected to additional $5 \times 3$ min cycles of sonication. After the completed sonication process, the mixture is poured into the mould and is placed in the freezer overnight. The next step is to place the sample in the freeze dryer at a temperature of $-91{ }^{\circ} \mathrm{C}$ to obtain the cellulose aerogel. After the freeze-drying process, the aerogel sample is placed in the oven for the cross-linking process. After $3 \mathrm{~h}$ at $120^{\circ} \mathrm{C}$, the aerogel sample can achieve its finalized thickness and shape as seen in Figure 3b. Mode details of the morphology and the properties of the cellulose aerogel can be found on our previous works [9-12]. 


\subsection{Design of Sandwich Structures}

For the internal layer, Nylon in Figure 3a is chosen over the others due to the lowest thermal conductivity value high durability, low cost, high availability and smooth texture [13]. Heavy-duty fabric of Neoprene, as seen in Figure 3c, is chosen as the external layer of the thermal jacket due to the low thermal conductivity, excellent durability, mostly weather proof, high abrasion and tear resistance [14]. More details of the layer material properties can be found in the Appendix A Table A3. Figure $3 \mathrm{~d}$ shows the proposed sandwich layer using different materials forming the insulated jacket.

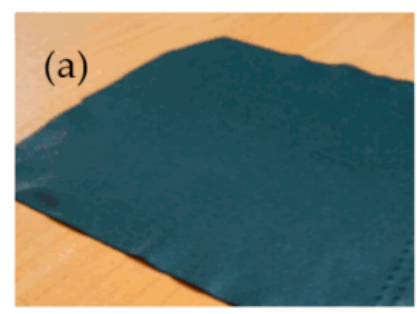

Nylon

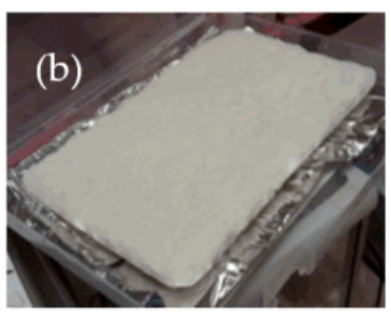

Cellulose aerogel

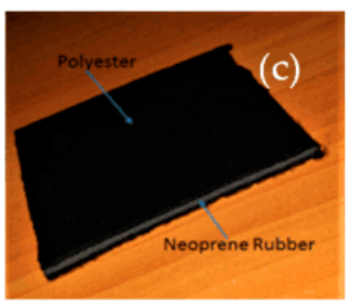

Neoprene

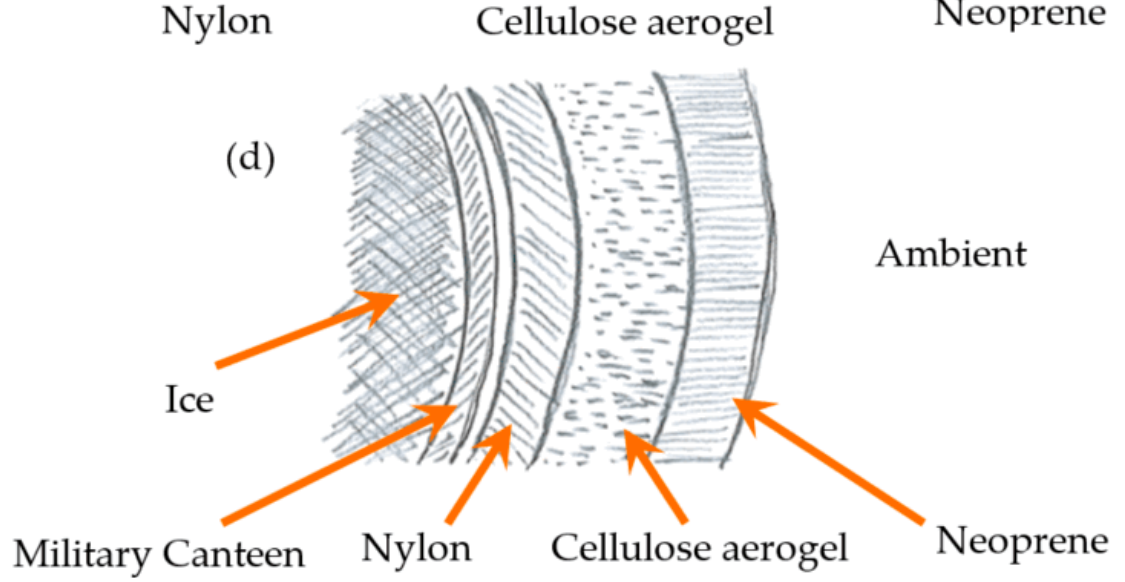

Figure 3. Materials of (a) nylon, (b) cellulose aerogel, (c) neoprene are used for the insulated jacket design, and (d) the sandwich structure consists of Neoprene as the outmost layer, the cellulose aerogel within and Nylon as the innermost layer.

\subsection{Prototype Fabrication Process of the Thermal Jacket}

The prototype fabrication has the following steps: (i) Cutting the inner and outer fabric into specifically-shaped panels in Figure 4a, (ii) Sewing the inner fabric pieces together to form an inner jacket, (iii) Wrapping the aerogel securely around the inner jacket, (iv) Sewing the outer fabric pieces and zipper together over the aerogel layer and with the inner jacket, and (v) Sewing the collar onto the neck of the assembly to complete the product. Straight stitch should not be applied as the straight stitch can tear the fabric easily because Neoprene and Nylon are stretchable. Hence, the zig-zag stitch method is preferred. The zipper is applied to allow the military canteen to be inserted and removed easily from the insulated jacket. The collar is used to reinforce the neck area. The components come together to form a final thermal jacket are shown in Figure $4 \mathrm{~b}$. 


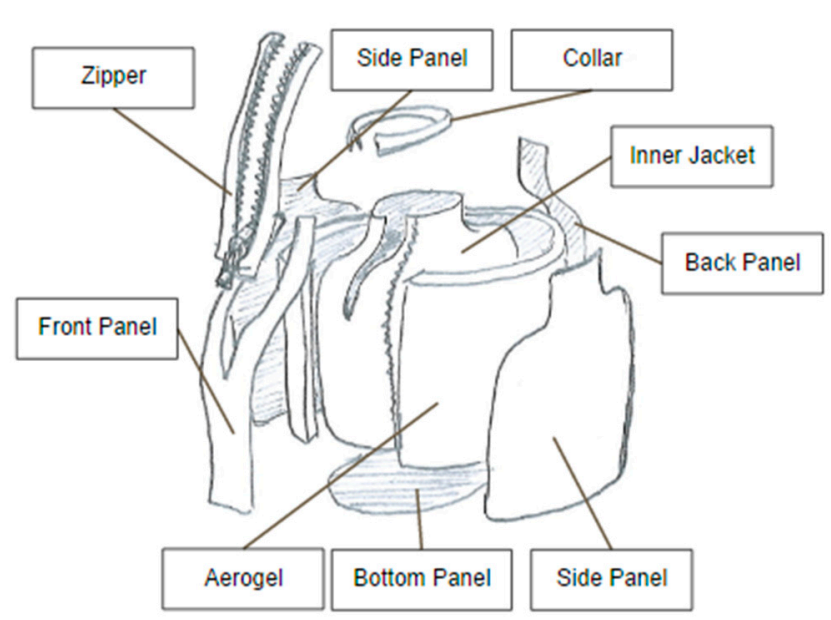

(a)

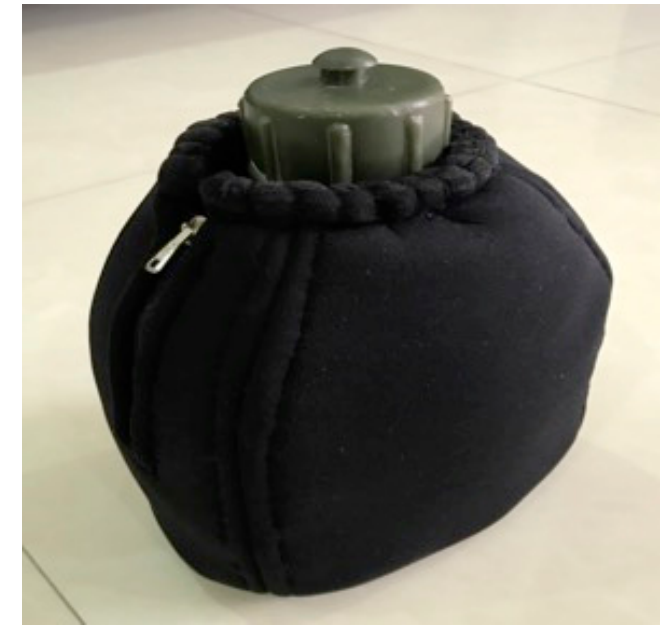

(b)

Figure 4. (a) Sketch of the insulated jacket and (b) final insulated jacket on the military canteen.

\subsection{Characterization}

The heat insulation test under static condition was conducted in a laboratory with an ambient temperature of $25^{\circ} \mathrm{C}$ for $4 \mathrm{~h}$. The content of the bottle is ice slurry, which comprises $1 / 3$ water and $2 / 3$ crushed ice and the temperature of the content of the bottle is recorded every $30 \mathrm{~min}$. Four bottles including the military canteen without the insulated jacket, the military canteen wrapped with the insulated jacket, the commercial FLOE bottle and the vacuum flask bottle were used in the experiments for comparison.

Water contact angle measurements are carried out on a VCA Optima goniometer (AST Products Inc., Billerica, MA, USA) to evaluate the water repellence of the methyltrimethoxysilane (MTMS)-coated aerogels. During the test, water drops of $0.5 \mu \mathrm{L}$ were controlled by the syringe system of the tester and were dispensed drop by drop onto the surface of the samples. The contact angle values were calculated using the contact angle meter software, which analyses the droplet shape in the image. For each sample, measurements were repeated at several different positions, and the contact angle was ultimately determined by averaging these contact angle values from the various measurements. In order to verify the moisture absorbency for the shortlisted fabrics, the VCA Optima was used to measure the contact angle of each fabric to determine which material will be most suitable for the shell and lining of the product.

The C-Therm TCi Thermal Conductivity Analyser (C-Therm Technologies Ltd., Fredericton, NB, Canada) was used for this work. It employs the Modified Transient Plane Source (MTPS) technique, which uses a one-sided interfacial heat reflectance sensor to apply a momentary constant heat source to the specimen and measure the $\mathrm{K}$ value from the rate of increase in the sensor voltage. The results achieved by the MTPS method are similar in accuracy to the traditional guarded hot plate apparatus.

\section{Conclusions}

After fabricating prototypes and analyzing the flaws of our design, the cost-effective insulated jacket with the effective heat insulation performance is developed successfully for mass production. Interestingly, the military canteen wrapped with the cellulose aerogel can match the insulation performance of the vacuum flask bottles after $4 \mathrm{~h}$, which is the average duration of an outfield exercise. The materials chosen in this work can withstand the harsh conditions of a jungle environment. Currently, soldiers have been equipped three-liter polyethylene water pouches. The insulated jacket developed in this work can be used for the water pouch so that soldiers may carry up to four liters of ice slurry during outfield operations instead of one liter of the insulated military canteen. Finally, 
the design concept of the insulated military canteen may be extended to other commercial bottles as well.

Acknowledgments: The authors would like to thank C-265-000-049-001 FB Funding and DSO National Laboratory for their research support.

Author Contributions: X.Z.C., T.K. and W.Z.L. conceived and designed the experiments; K.H.W. and N.G.N. performed the experiments; H.M.D. and W.Z.L. analyzed the data; H.J.L., K.S.C. and A.H.L. contributed reagents/materials/analysis tools; H.M.D wrote the paper.

Conflicts of Interest: The authors declare no conflict of interest.

\section{Appendix A}

Table A1. Property comparison of various bottles.

\begin{tabular}{|c|c|c|c|}
\hline \multirow[b]{2}{*}{ Parameters } & \multirow[t]{2}{*}{ Military Canteen [4] } & Floe Bottle [6] & \multirow[t]{2}{*}{ Vacuum Flask [5] } \\
\hline & & & \\
\hline Thermal conductivity, $\mathrm{W} / \mathrm{m} \cdot \mathrm{K}$ & 0.33 & 0.14 & - \\
\hline Cost, $\mathrm{S} \$$ & $\$ 1.52$ & $\$ 98.00$ & $\$ 50.00$ \\
\hline Capacity, L & 1.0 & 1.0 & 1.0 \\
\hline Weight, g & 160 & 500 & 900 \\
\hline
\end{tabular}

Table A2. Estimated cost of manufacturing the insulated jacket.

\begin{tabular}{ccccc}
\hline S/N & Items & Unit Cost, S\$ & Quantity & Cost, S\$ \\
\hline 1 & Military Canteen Bottle & $\mathrm{S} \$ 1.52 / \mathrm{bottle}$ & 1 & 1.52 \\
2 & Polyester Fabric & $\mathrm{S} \$ 1.40 / \mathrm{m}^{2}$ & 0.100 & 0.14 \\
3 & Recycled Cellulose & $\mathrm{S} \$ 4.36 / \mathrm{kg}$ & 0.0287 & 0.13 \\
4 & Kymene & $\mathrm{S} \$ 1.05 / \mathrm{kg}$ & 0.0057 & 0.01 \\
5 & MTMS & $\mathbf{S} \$ 2.24 / \mathrm{kg}$ & 0.143 & 0.32 \\
6 & Zipper & $\mathrm{S} \$ 0.46 / \mathrm{m}$ & 0.100 & 0.05 \\
7 & Neoprene (3-mm thickness) & $\mathrm{S} \$ 3.02 / \mathrm{m}^{2}$ & 0.100 & 0.30 \\
8 & Manpower & $\mathrm{S} \$ 2.93 / \mathrm{h}$ & 0.5 & 1.47 \\
9 & Electricity & $\mathrm{S} \$ 0.13 / \mathrm{kWh}$ & 47.8 & 6.21 \\
10 & Water $\$ 0.73 / \mathrm{m}^{3}$ & 0.0029 & 0.05 \\
\hline \multicolumn{4}{c}{ Total cost estimation } \\
\hline
\end{tabular}

Table A3. Insulating Material Selection.

\begin{tabular}{|c|c|c|c|}
\hline Material Selection Criteria & Cellulose Aerogel [9-12] & Neoprene Fabric [14] & Nylon Fabric [13] \\
\hline Thermal conductivity $(\mathrm{W} / \mathrm{m} \cdot \mathrm{K})$ & 0.03 & 0.047 & 0.046 \\
\hline Density $\left(\mathrm{g} / \mathrm{cm}^{3}\right)[6]$ & 0.04 & - & - \\
\hline Durability & Fair & Excellent & Good \\
\hline Stretchability & Fair & Excellent & Excellent \\
\hline Low Cost and availability & $\begin{array}{c}\text { Yes but no availability in } \\
\text { the market }\end{array}$ & $\begin{array}{c}\text { Yes and availability in } \\
\text { the market }\end{array}$ & $\begin{array}{l}\text { Yes and availability } \\
\text { in the market }\end{array}$ \\
\hline
\end{tabular}

\section{References}

1. Heat Stroke: Symptoms and Treatment. Available online: https://www.webmd.com/a-to-z-guides/heatstroke-symptoms-and-treatment\#1 (accessed on 1 November 2017). 
2. Lee, J.K.W.; Kennefick, R.W.; Cheuvront, S.N. Novel cooling strategies for military training and operations. J. Strength Cond. Res. 2015, 29, S77-S81. [CrossRef] [PubMed]

3. Dugas, J. Ice slurry ingestion increases running time in the heat. Clin. J. Sport Med. 2011, 21, 541-542. [CrossRef] [PubMed]

4. Seah, K.H. Fundamental Principles of Manufacturing, 1st ed.; Cobee Publishing House: Singapore, 2015; ISBN 9789810959050.

5. Best Insulated Water Bottles—Our Top Picks, Hydration Anywhere. Available online: https:/ /hydrationanywhere. com/best-insulated-water-bottle-our-top-picks / (accessed on 1 November 2017).

6. Floe Bottle. Available online: https:/ /www.floebottle.com/ (accessed on 1 November 2017).

7. Beer Koozies Do Help Keep Your Drink Cold—But Not The Way You Think They Do. Available online: http:// www.ibtimes.com/beer-koozies-do-help-keep-your-drink-cold-not-way-you-think-they-do-1220253 (accessed on 1 November 2017).

8. Five Most Common Thermal Insulation Materials. Available online: https://www.thermaxxjackets.com/5most-common-thermal-insulation-materials / (accessed on 1 November 2017).

9. Feng, J.; Nguyen, S.T.; Fan, Z.; Duong, H.M. Advanced fabrication and oil absorption properties of super-hydrophobic recycled cellulose aerogels. Chem. Eng. J. 2015, 270, 168-175. [CrossRef]

10. Duong, H.M.; Nguyen, S.T. Nano and Biotech Based Materials for Energy Building Efficiency; Springer International Publishing: Cham, Switzerland, 2016; pp. 411-427, ISBN 978-3-319-27505-5.

11. Nguyen, S.T.; Feng, J.; Le, N.; Le, A.T.; Hoang, N.; Duong, H.M. Cellulose aerogel from paper waste for crude oil spill cleaning. Ind. Eng. Chem. Res. 2013, 52, 18386-18391. [CrossRef]

12. Nguyen, S.T.; Duong, H.M.; Tan, V.B.C.; Ng, S.K.; Wong, J.P.W.; Feng, J. Advanced thermal insulation and absorption properties of recycled cellulose aerogels. Colloids Surf. A Physicochem. Eng. Asp. 2014, 445, 128-134. [CrossRef]

13. Nylon vs. Polyester. Available online: http://www.diffen.com/difference/Nylon_vs_Polyester (accessed on 1 November 2017).

14. Neoprene Rubber Polymer. Available online: http://www.warco.com/polymer/neoprene/ (accessed on 1 November 2017).

(C) 2017 by the authors. Licensee MDPI, Basel, Switzerland. This article is an open access article distributed under the terms and conditions of the Creative Commons Attribution (CC BY) license (http:/ / creativecommons.org/licenses/by/4.0/). 